\title{
Gemcitabine and Doxorubicin Combination Enhance the Cytotoxic Effect to Pancreatic Cancer Cells BxPC3 and PANC1 through UMP/CMP Kinase 1
}

\author{
Shuxian Chen, Xu Wang, Xianghui Ye, Jian Jin \\ Laboratory of Molecular Pharmacology, School of Pharmaceutical Science, Jiangnan University, Wuxi, China \\ Email:243839576@qq.com, 525328416@qq.com,1587323397@qq.com,jinjian31@163.com
}

How to cite this paper: Chen, S.X., Wang, X., Ye, X.H. and Jin, J. (2017) Gemcitabine and Doxorubicin Combination Enhance the Cytotoxic Effect to Pancreatic Cancer Cells BxPC3 and PANC1 through UMP/ CMP Kinase 1. Journal of Biosciences and Medicines, 5, 64-74.

https://doi.org/10.4236/jbm.2017.510007

Received: August 25, 2017

Accepted: October 24, 2017

Published: October 27, 2017

Copyright $\odot 2017$ by authors and Scientific Research Publishing Inc. This work is licensed under the Creative Commons Attribution International License (CC BY 4.0).

http://creativecommons.org/licenses/by/4.0/

\begin{abstract}
Background: Gemcitabine is a deoxycytidine analog, which is used as first-line agent for pancreatic cancer therapy, and its efficacy relied on its intracellular conversion to active triphosphate form. However, administration with gemcitabine still has limited effect on the overall survival of patients with pancreatic cancer. Objective: We aimed to study the combination effect of gemcitabine and doxorubicin to pancreatic cancer cells BxPC3 and PANC1, and unveil the mechanism. Methods: The study was performed in pancreatic cancer cells PANC1 and BxPC3, the contribution of UMP/CMP kinase 1 (CMPK1) to gemcitabine in PANC1 and BxPC3 cells was measured by transfection of CMPK1 plasmid or CMPK1 siRNA treatment to adjust the expression of CMPK1 in the cells; then analyzed the cell vitality and migration after treated with $1 \% \mathrm{IC}_{50}$ of doxorubicin and gemcitabine or only with gemcitabine; the activity of CMPK1 and the effect of doxorubicin to the reaction was measured by HPLC assay in vitro; at last, docking analysis by computer was used to calculate the possible interaction sites of CMPK1 to DOX. Results: The sensitivity of PANC1 and BxPC3 cells to gemcitabine was improved when increasing the expression of CMPK1, and decreased when knockout CMPK1 by CMPK1 siRNA in BxPC3 cells; when combined with doxorubicin, the sensitivity of PANC1 and BxPC3 cells to gemcitabine also increased, and the cells migration reduced; we further found out that by adding $10 \mu \mathrm{M}$ doxorubicin, the catalyzing activity of CMPK1 elevated about 2 times in vitro; the docking result showed that the association of CMPK1 to DOX was mainly by hydrogen bond and ionic interaction. Conclusion: CMPK1 can catalyze gemcitabine to its active form within the cells so that the sensitivity of the cells to gemcitabine elevated, and doxorubicin may enhance the cytotoxic effect to pancreatic cancer
\end{abstract}


by up-regulate the activity of CMPK1, the combination of these deoxycytidine analogs with DOX might exert better efficacy.

\section{Keywords}

Gemcitabine, Deoxycytidine Analog, Doxorubicin, CMPK1, Pancreatic Cancer

\section{Introduction}

Pancreatic cancer is fatal for patients with a median survival of less than 6 months [1], and has become one of the most devastating and deadly forms of cancers, and has an aggressive course predominantly seen in men at advanced age (40 - 85 years) [2]. The highest incidence and mortality rates of pancreatic cancer are found in developed countries. Although the immune system [3] is considered to play an important role in the development and progression of pancreatic cancer, and many risk factors have also been identified, such as genetics, obesity, smoking, diabetes, inactivity [4], the causes of pancreatic cancer are still insufficiently known. Curative surgery is nearly impossible because of its highly aggressive locoregional invasion [5], and the treatments focusing on pancreatic cancer cells alone have failed to significantly improve patient outcome over many decades, more effective treatments are desperately needed.

Gemcitabine (2', 2'-difluorodeoxycytidine) has emerged as the first line treatment of pancreatic cancers. Gemcitabine belongs to pyrimidine analogs, which require stepwise phosphorylation to the respective triphosphate metabolites to exert their pharmacological activity: gemcitabine is phosphorylated to its monophosphate (dFdCMP) form by the deoxycytidine kinase (DCK), CMPK1 converts it to the active diphosphate form ( $\mathrm{dFdCDP}$ ), other nucleoside kinases further phosphorylate dFdCDP to its another active triphosphate (dFdCTP) forms [6]. Deoxyribonucleoside triphosphates are critical for DNA and RNA synthesis. The importance of nucleoside analogs in the inhibition of viral replication and treatment of cancer has been recognized [7]. However, efficacy of gemcitabine for advanced and metastatic pancreatic cancer is limited. After injection, gemcitabine is often confronted with poor phosphorylation to its active triphosphate metabolite [1].

CMPK1 is thought to play a major role in the activation of gemcitabine and its cytotoxicity, and is a rate limiting enzyme in the conversion of gemcitabine to triphosphate form in the cell [8] [9]. CMPK1 is part of pyrimidine nucleotide interconversion pathway, which catalyzes the phosphoryl transfer from adenosine-5'-triphosphate (ATP) to cytidine 5'-monophoaphate (CMP), 2'-deoxy-CMP (dCMP), uridine 5'-monophosphate (UMP) or other pyrimidine nucleotide analogs [10]. Many of these analogs are important anticancer and antiviral agents include gemcitabine. Furthermore, $\beta$-L-dioxaolanetibine (L-OddC) and 
$\beta$-L-2', 3'-dideoxy-3'-thiacytidine (3-TC) are active anti-human immunodeficiency virus (HIV) and anti-human hepatitis $B$ virus agents. Cytidine analog $1-\beta$-D-arabinofuranosylcytosine (AraC) [11] [12] has shown to be active against acute leukemia therapy. It has been found that low expression of CMPK1 in HCT- 8 and Hela S3cells are related to pyrimidine analogs resistance by reducing the formation of triphosphate metabolites [13]. The subcellular localization of CMPK1 has been found to be important for cancer progress which may be related to dysregulation of ECM and cell cycle molecules [14]. CMPK1 has also been identified as a prognostic marker for lymph-node negative (LNN) [15] and adjuvant systemic chemotherapy naive (ASCN) triple negative breast cancer (TNBC) patients [16].

Doxorubicin (DOX) is an anthracycline with complicated structure. Science it used as clinical agent in 1970s, doxorubicin has shown potential activity in anti-cancer therapy [17]. The mechanism of DOX was controversial. It is still broadly investigated by many research groups including ours [18] [19]. In our former work, we have screened the targets of DOX by high density protein array which contains 17,950 kinds of proteins [20]. We have first found out that CMPK1 was one of its targets, and DOX showed positive activation of CMPK1 in the phosphorylation of pyrimidine analogs from monophosphates to their diphosphate metabolites in vitro.

In this article, we aimed to investigate the contribution of CMPK1 to gemcitabine, and the contribution of DOX to CMPK1 dependent gemcitabine treatment. Knowing the relationship of gemcitabine, DOX and CMPK1 would guide pyrimidine analogs treatment to pancreatic cancer as well as other carcinomas.

\section{Materials and Methods}

\subsection{Materials}

The pancreatic cancer cells BxPC3 and PANC1 were gifts from Suzhou university school of medicine (Suzhou, China); Gemcitabine was purchased from Aladdin (Shanghai, China); Doxorubicin was purchased from Meilun (Dalian, China); Cell vitality assay kit was a product of Promega (America); DDK (DYKDDDDK) and CMPK1 antibody were gifts from Origene Technology (America); CMPK1 siRNA was a product of Santa Cruze (America); transfection reagent lipofectamine 2000 and opti-MEM medium were products of Invitrogen (America); CMPK1 protein was a product of Sino Biological (Beijing, China); CMP\&CDP\&CTP HPLC standard was a product of Sigma (America).

\subsection{Cell Culture and Growth Inhibition Assay}

BxPC3 and PANC1 cells were cultured in DMEM medium supplemented with $10 \%$ fetal bovine serum, and maintained at $37^{\circ} \mathrm{C}, 5 \% \mathrm{CO}_{2}$ with saturated humidity.

Cells were cultured by $8 \times 10^{3}$ cells/well in 96 -well plate. $100 \mu \mathrm{L}$ serially diluted drugs in triplicate were added to cells in logarithmic growth. After $48 \mathrm{~h}$ 
culture, $10 \mu \mathrm{L}$ cell titer blue reagent was added to each well. The florescence density (excitation: $560 \mathrm{~nm}$; emission: $590 \mathrm{~nm}$ ) of each well was determined by using a microplate reader (Molecular Devices, Sunnyvale, CA, USA). Cell growth relative to control was calculated by dividing the florescence values in drug-treated wells by those in control wells. Data were plotted as a percentage of cell growth versus drug concentration.

\subsection{DNA Transfection}

Put $4-5 \times 10^{5} \mathrm{BxPC}_{3}$ or PANC1 cells in $6 \mathrm{~mm}$ plate with growth medium one day before transfection, and when they grow to $90 \%$ - 95\% confluent, discard former medium and use the medium without serum and antibiotics instead. Dilute $8 \mu \mathrm{g}$ siRNA with $500 \mu \mathrm{L}$ OPTI-MEM medium, then dilute $20 \mu \mathrm{L}$ of lipofectamine 2000 with $500 \mu \mathrm{L}$ Opti-MEM medium, incubate for $5 \mathrm{~min}$ in room temperature, combine the diluted siRNA with diluted lipofectamine 2000, and incubate for another $20 \mathrm{~min}$. Add the complexes into the plate with cells and medium. Incubate cells at $37^{\circ} \mathrm{C}$ in a $\mathrm{CO}_{2}$ incubator for $18-48 \mathrm{~h}$ prior to test for transgene expression.

\subsection{CMPK1 siRNA Treatment}

CMPK1 siRNA treatment was done as DNA transfection. Instead by diluting 200 pmol siRNA with $500 \mu \mathrm{L}$ opti-MEM medium, and diluting $10 \mu \mathrm{L}$ of lipofectamine 2000 with $500 \mu \mathrm{L}$ opti-MEM medium.

\subsection{Western Blotting}

For western blot analysis, cells were lysed with RIPA (20 mM PBS at pH 7.5, 300 $\mathrm{mM} \mathrm{NaCl}, 5 \mathrm{mM}$ EDTA, 10\% glycerol, $1 \%$ Triton X-100, 1\% PMSF) in ice for 10 $\mathrm{min}$, then centrifuged in $12,000 \mathrm{~g}, 4^{\circ} \mathrm{C}$ for $10 \mathrm{~min}$. The supernatant was tested by electrophoresis and immune-blot with primary antibodies and respective second antibodies. Chemiluminescence detection was done through a CCD camera using the ChemiDoc System (Bio-Rad) with Image Lab software (Bio-Rad, version 4.0).

\subsection{Cell Migration Assay}

The cells were collected by standard trypsinization when they grow to exponential phase. Wash them by PBS, suspend the cells by the medium without serum to the concentration of about $2 \times 10^{5} / \mathrm{mL}$. Add $800 \mu \mathrm{L}$ of medium contain $10 \%$ FBS to the lower chamber of the 24-well plate, insert the transwell to the 24-well plate as up chamber, add $150 \mu \mathrm{L}$ of suspended cells into the tanswells, and treat the cells with related drugs. Take out the transwells, carefully erase the cells in the bottom of the membrane, and stained the cells by crystal violet.

\subsection{CMPK1 Activity Assay by HPLC}

The assay of CMPK1 activity was performed in $300 \mu \mathrm{L}$ of $50 \mathrm{mM}$ Tris-acetate, $\mathrm{pH}$ 7.5, $2 \mathrm{mM} \mathrm{MgCl}$. ATP $(2 \mathrm{mM})$ was used as phosphate donor, DOX $(10 \mu \mathrm{M})$ 
was used as regulator, the reaction without DOX was set as control, and the concentration of DOX was determined in our former work [20]. CMPK1 (2 $\mathrm{nM})$, (d) CMP (1 mM), UMP (1 mM) were added to initiate the reaction. The reaction mixture was incubated at $37^{\circ} \mathrm{C}$ for $2 \mathrm{~min}-120 \mathrm{~min}$ and stopped by the addition of $100 \mu \mathrm{L}$ of $45 \%$ trichloroacetic acid and chilled on ice. The activity was determined by analysis of the product by HPLC (Agilent 1260) with a ZORBAX C18 column $(4.6 \times 250 \mathrm{~mm}, 5 \mu \mathrm{m}$; Agilent, Santa Clara, CA). Methanol with $0.6 \%$ phosphoric acid (6:94, $\mathrm{pH}$ adjusted to 6.6 by triethylamine) was used as mobile phase. The nucleotide phosphates were detected by ultraviolet light absorbance at $271 \mathrm{~nm}$ and quantified by comparison to standards.

\subsection{Docking Analysis}

Down load the crystal structure of CMPK1 (PDB ID:1TEV) and 3-D structure of DOX from PDB and PUMchem. Prepare protein and small molecular by Discovery studio 3.5 (DS), respectively. And use the tool of DS Find Sites to find out the possible association site of CMPK1 and DOX.

\subsection{Statistical Analysis}

Data was calculated by GraphPad Prism 6.0, Comparison of numerical data was done by using student $t$-test, The $P$ value was considered significant if it was less than 0.05 .

\section{Results}

\subsection{The Activity of Gemcitabine Was Regulated by CMPK1}

BxPC3 and PANC1 cells were transfected with CMPK1 plasmid which contained DKKDDDDK (DDK) tail. After transfection, the growth inhibition of gemcitabine to the cells was analyzed. Both BxPC3 and PANC1 cells expressed extra CMPK1 and showed increased sensitivity to gemcitabine (Figure 1(a) and Figure $1(\mathrm{~b}))$.

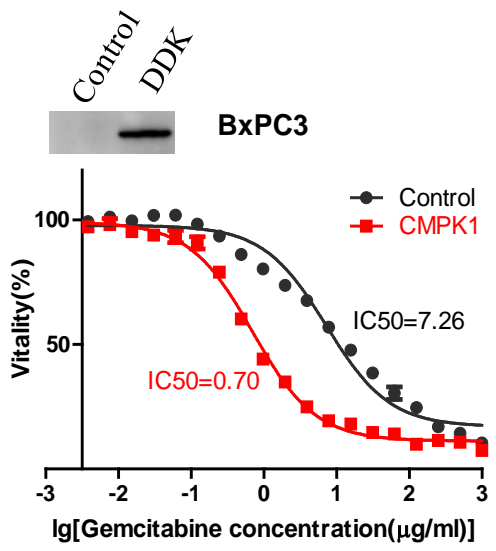

(a)

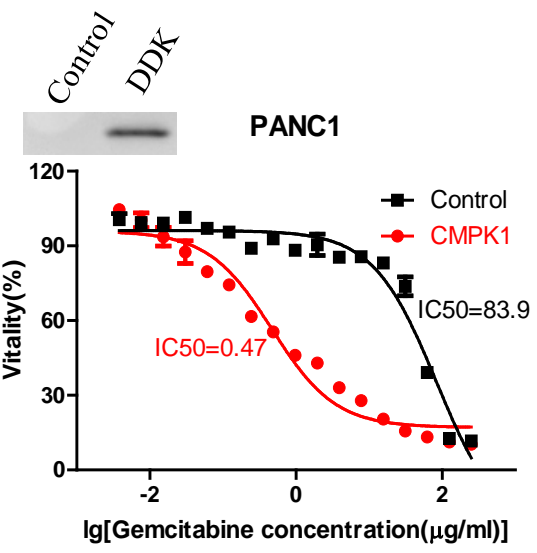

(b)

Figure 1. Over-expression of CMPK1 increased the sensitivity of BxPC3 cells (a) and PANC1 cells (b) to gemcitabine. 
We decreased the CMPK1 by CMPK1 siRNA in BxPC3 for its IC $_{50}$ was relatively low, the $\mathrm{IC}_{50}$ of $\mathrm{BxPC} 3$ to gemcibatine increased responded to the decreased expression of CMPK1 in the cells (Figure 2).

\subsection{Gemcitabine and Doxorubicin Combination Enhanced the Cytotoxic Effect to Pancreatic Cancer Cells BxPC3 and PANC1}

BxPC3 and PANC1 cells were treated with $1 \% \mathrm{IC}_{50}$ of DOX and serially diluted gemcitabine, cells only treated with gemcitabine were set as control. BxPC3 and PANC1 cells both showed decreased $\mathrm{IC}_{50}$ of gemcitabine (Figure 3(a) and Figure 3(b)) with significant differences (Figure 3(c)).

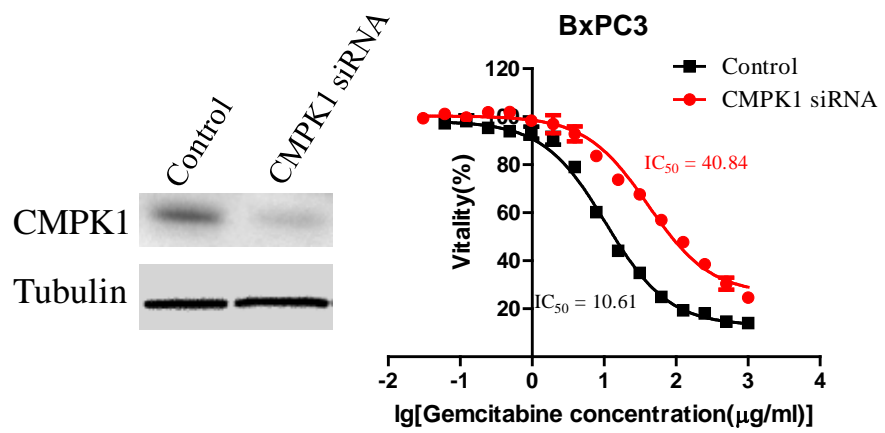

Figure 2. BxPC3 was transfected with CMPK1 siRNA, and the $\mathrm{IC}_{50}$ of $\mathrm{BxPC} 3$ to gemcitabine was increased responded with decreased expression of CMPK1.

BxPC3

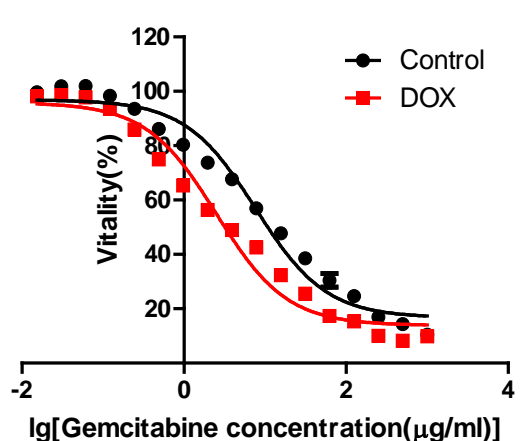

(a)
PANC1

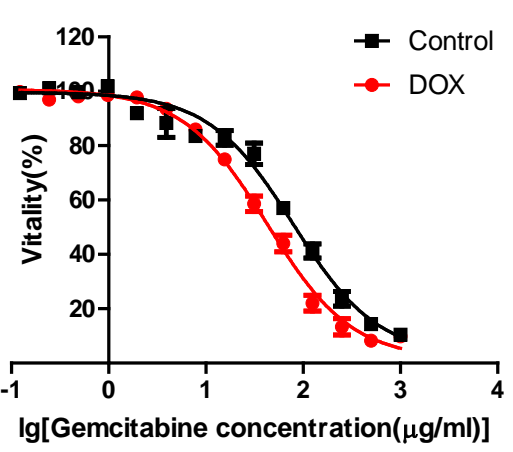

(b)

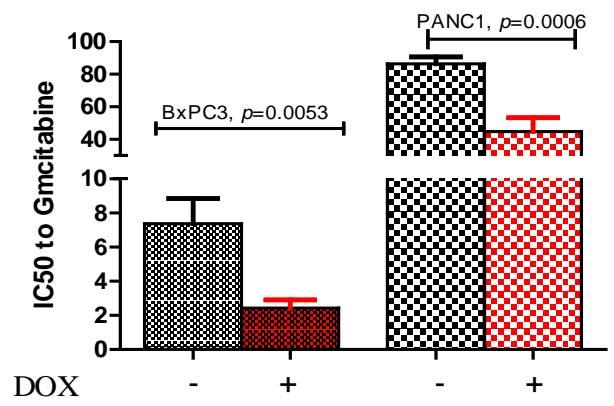

(c)

Figure 3. IC50 assay of BxPC3 cells (a) and PANC1 cells (b) to gemcitabine when treated with DOX or not; (c) Histogram of $\mathrm{IC}_{50}$ values of BxPC3 and PANC1 cells. 


\subsection{The Migration of PANC1cells Were Decelerated when Co-Treated by DOX and Gemcitabine}

From Figure 4, we can see the migration of PANC1 cells were not affected when treated only with $\mathrm{ADM}$, while the concentration of $\mathrm{ADM}$ was $1 \% \mathrm{IC}_{50}$ to cells. But with the addition of gemcitabine, the migration of cells decreased in dose dependent manner. So the combination of gemcitabine with ADM may increase the effect of gemcitabine itself.

\subsection{The Activity of CMPK1 Was Up-Regulated by DOX}

CMP, dCMP and UMP are substrates of CMPK1; they can get phosphorylation (Figure 5(a)) by CMPK1 as dFdCMP. When DOX added to the reaction, the activity of CMPK1 up-regulated to about 2 times compared with control no matter the substrate were CMP, dCMP or UMP (Figure 5(b)).
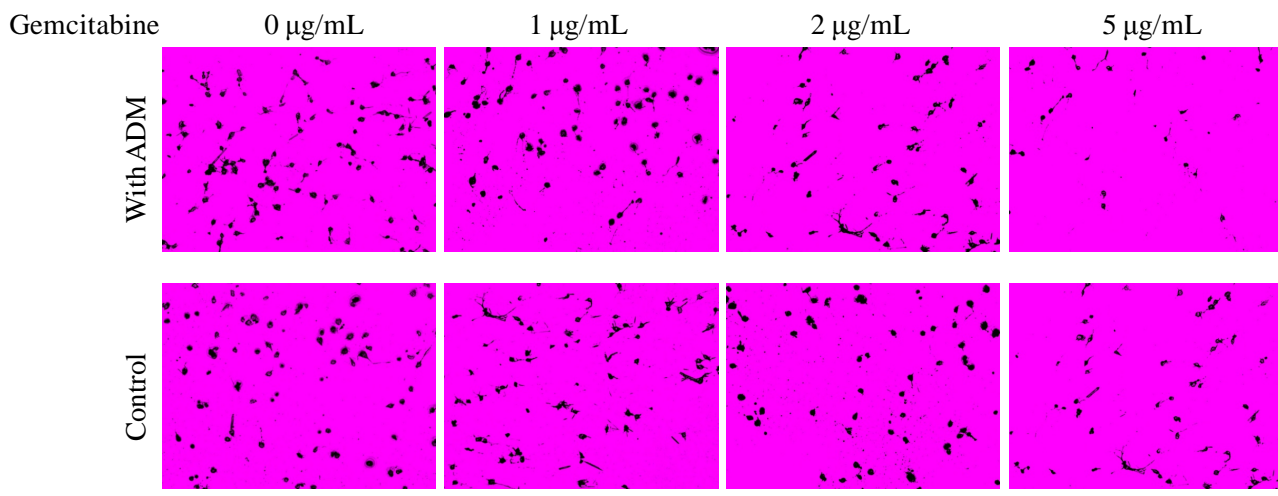

Figure 4. The cell migration of PANC1 cells after $24 \mathrm{~h}$ treatment by gemcitabine $(0 \mu \mathrm{g} / \mathrm{mL}, 1$ $\mu \mathrm{g} / \mathrm{mL}, 2 \mu \mathrm{g} / \mathrm{mL}, 5 \mu \mathrm{g} / \mathrm{mL}$ ) or gemcitabine combined with ADM ( $1 \%$ cell $\left.\mathrm{IC}_{50}\right)$, respectively. The cells treated with only gemcitabine but no combination with ADM was set as control.

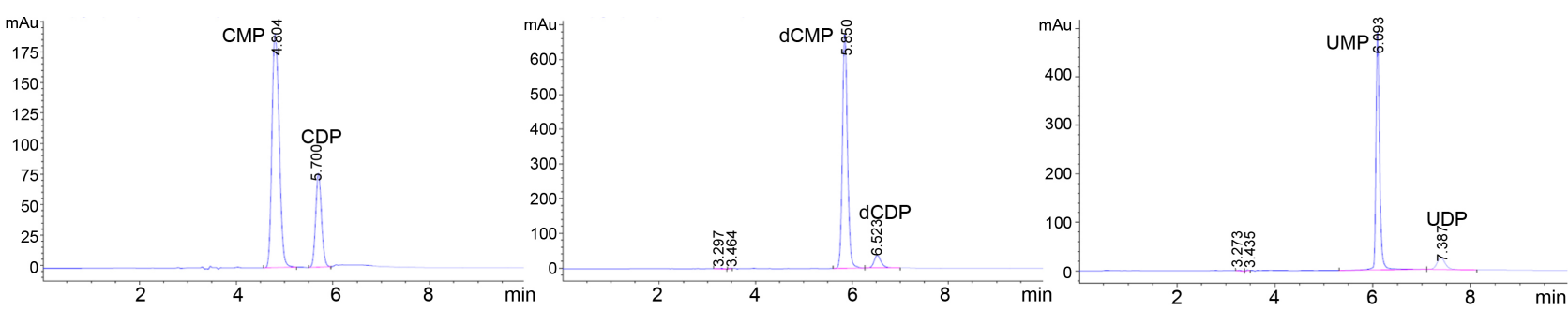

(a)

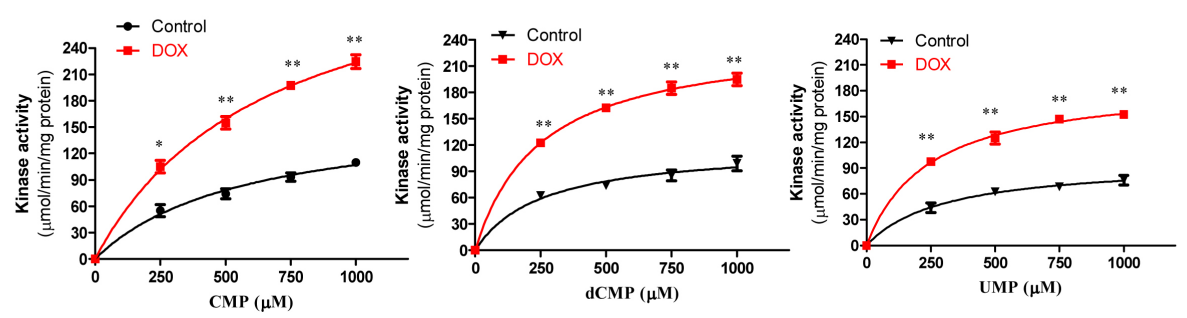

(b)

Figure 5. The activity of CMPK1 activated by dox. (a) HPLC results of related substrates and products of the reaction; (b) The kinase activity of CMPK1 regulated by DOX. Experiments were done in triplicate (duplicate experiments). 


\subsection{Docking Analysis of CMPK1 and DOX}

There were 2 docking results: site 1 and site 2. Use DS CDOCKER to analyze the docking results. In site 1 (Figure 6(a)), Gly13, Arg151, Asp142, Arg39 formed strong hydrogen bond with DOX, furthermore, Asp143 formed strong ionic interaction with DOX, these interaction caused strong combination of DOX and CMPK1; However, another result site 2 (Figure 6(b)) showed that DOX formed hydrogen interaction with only Asp113 and Asp 109, the relationship between each significantly less than site 2 .

\section{Discussions}

Gemcitabine was a representative drug of nucleotide analog but its efficacy limited when treated with progressed and metastatic cancers, it was mainly because the expression of CMPK1 became lower, so that the phosphorylation of gemcitabine to its active form affected. We have studied the combination of DOX and gemcitabine to pancreatic cancer, and found that the expression of CMPK1 in the cells regulated the action of gemcitabine. Furthermore, the combination of gemcitabine and DOX was more efficient than single treatment of gemcitabine, which may be related to the association of DOX. It has been reported [21] that Doxorubicin and gemcitabine combination can decrease proliferation, increase apoptosis in the MCF7 main population and stem-like side population cells, inhibited tumor growth and improved the survival rate of mice

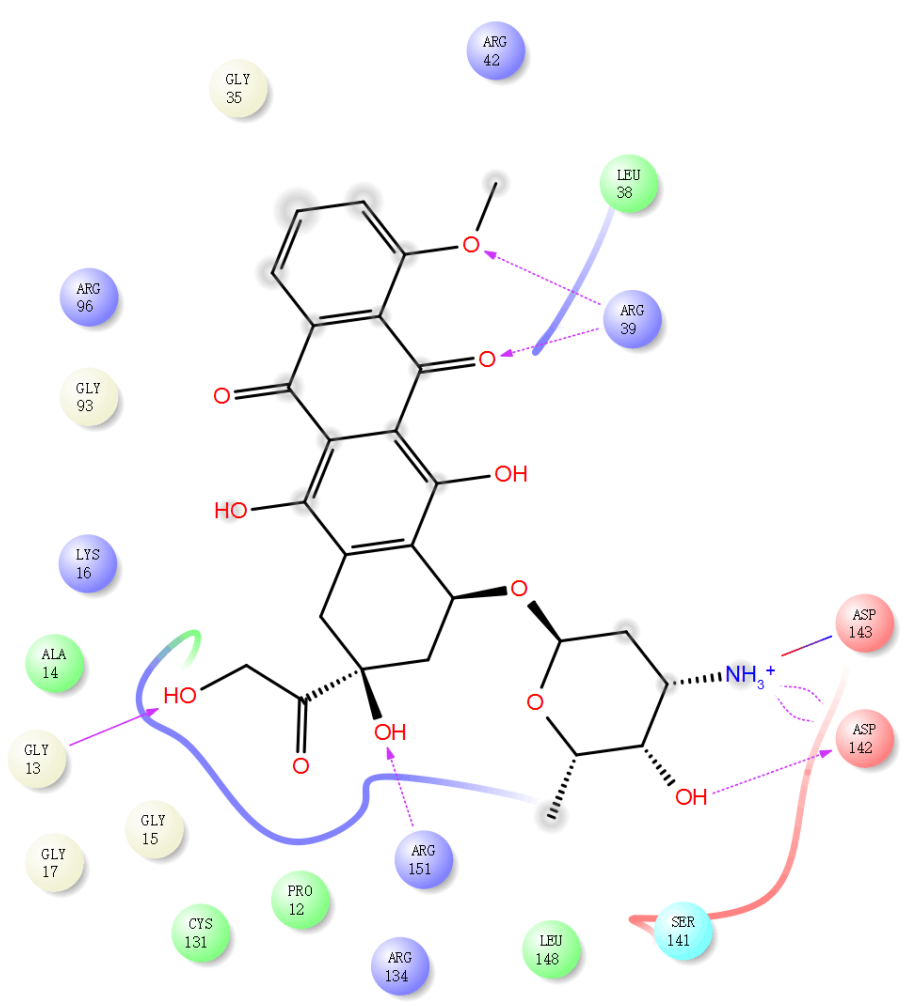

(a)

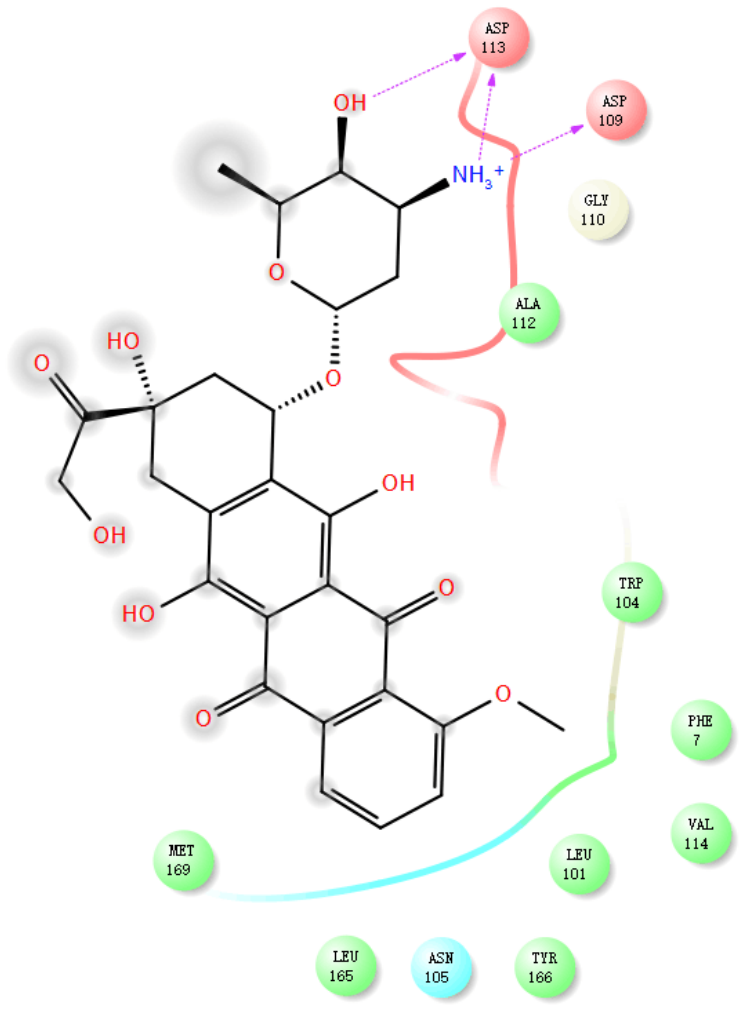

(b)

Figure 6. Docking analysis of the binding sites of DOX and CMPK1 by computer. (a) Site 1; (b) Site 2. 
in vivo, and showed activity in aggressive renal tumors [22]. Many trials have been showed the advantages of such combination, but less explanations of the phenomenon, we unveiled one mechanism in this paper for better understanding.

On the other hand, we concluded that for most pyrimidine analogs, not just gemcitabine, the combination of these drugs with DOX may also showed great effect for they can be activated by CMPK1 through the association with DOX.

\section{Conclusion}

Dox combination with pyrimidine analogs may be more efficient for the activation effect of CMPK1 in cells and can be elevated by the association of CMPK1 and doxorubicin.

\section{Declaration of Conflicting Interests}

The authors declared no potential conflicts of interest with respect to the research, authorship, and/or publication of this article.

\section{References}

[1] Réjiba, S., Bigand, C., Parmentier, C. and Hajri, A. (2009) Gemcitabine-Based Chemogene Therapy for Pancreatic Cancer Using Ad-dCK::UMK GDEPT and TS/RR siRNA Strategies. Neoplasia, 11, 637-650. https://doi.org/10.1593/neo.81686

[2] Goral, V. (2015) Pancreatic Cancer: Pathogenesis and Diagnosis. Asian Pacific Journal of Cancer Prevention, 16, 5619-5624. https://doi.org/10.7314/APJCP.2015.16.14.5619

[3] Inman, K.S., Francis, A.A. and Murray, N.R. (2014) Complex Role for the Immune System in Initiation and Progression of Pancreatic Cancer. World Journal of Gastroenterology, 20, 11160-11181. https://doi.org/10.3748/wjg.v20.i32.11160

[4] Ilic, M. and Ilic, I. (2016) Epidemiology of Pancreatic Cancer. World Journal of Gastroenterology, 22, 9694-9705. https://doi.org/10.3748/wjg.v22.i44.9694

[5] Kollmannsberger, C., Peters, H.D. and Fink, U. (1998) Chemotherapy in Advanced Pancreatic Adenocarcinoma. Cancer Treatment Reviews, 24, 133-156. https://doi.org/10.1016/S0305-7372(98)90079-2

[6] de Sousa Cavalcante, L. and Monteiro, G. (2014) Gemcitabine: Metabolism and Molecular Mechanisms of Action, Sensitivity and Chemoresistance in Pancreatic Cancer. European Journal of Pharmacology, 741, 8-16. https://doi.org/10.1016/j.ejphar.2014.07.041

[7] Muggia, F., Diaz, I. and Peters, G.J. (2012) Nucleoside and Nucleobase Analogs in Cancer Treatment: Not Only Sapacitabine, But Also Gemcitabine. Expert Opinion on Investigational Drugs, 21, 403-408. https://doi.org/10.1517/13543784.2012.666236

[8] Hsu, C.H., Liou, J.Y., Dutschman, G.E. and Cheng, Y.C. (2005) Phosphorylation of Cytidine, Deoxycytidine, and Their Analog Monophosphates by Human UMP/CMP Kinase Is Differentially Regulated by ATP and Magnesium. Molecular Pharmacology, 67, 806-814. https://doi.org/10.1124/mol.104.006098

[9] Ohmine, K., Kawaguchi, K., Ohtsuki, S., Motoi, F., Ohtsuka, H., Kamiie, J., Abe, T., Unno, M. and Terasaki, T. (2015) Quantitative Targeted Proteomics of Pancreatic 
Cancer: Deoxycytidine Kinase Protein Level Correlates to Progression-Free Survival of Patients Receiving Gemcitabine Treatment. Molecular Pharmaceutics, 12, 3282-3291. https://doi.org/10.1021/acs.molpharmaceut.5b00282

[10] Segura-Peña, D., Sekulic, N., Ort, S., Konrad, M. and Lavie, A. (2004) SubstrateInduced Conformational Changes in Human UMP/CMP Kinase. The Journal of Biological Chemistry, 279, 33882-33889. https://doi.org/10.1074/jbc.M401989200

[11] Liou, J.Y., Dutschman, G.E., Lam, W., Jiang, Z. and Cheng, Y.C. (2002) Characterization of Human UMP/CMP Kinase and Its Phosphorylation of D- and L-Form Deoxycytidine Analogue Monophosphates. Cancer Research, 62, 1624-1631.

[12] Curbo, S., Amiri, M., Foroogh, F., Johansson, M. and Karlsson, A. (2003) The Drosophila Melanogaster UMP-CMP Kinase cDNA Encodes an N-Terminal Mitochondrial Import Signal. Biochemical and Biophysical Research Communications, 311, 440-445.

[13] Liou, J.Y., Lai, H.R., Hsu, C.H., Chang, W.L., Hsieh, M.J., Huang, Y.C. and Cheng, Y.C. (2010) Modulation of Human UMP/CMP Kinase Affects Activation and Cellular Sensitivity of Deoxycytidine Analogs. Biochemical Pharmacology, 79, 381-388.

[14] Humeniuk, R., Menon, L.G., Mishra, P.J., Gorlick, R., Sowers, R., Rode, W., Pizzorno, G., Cheng, Y.C., Kemeny, N., Bertino, J.R. and Banerjee, D. (2009) Decreased Levels of UMP Kinase as a Mechanism of Fluoropyrimidine Resistance. Molecular Cancer Therapeutics, 8, 1037-1044. https://doi.org/10.1158/1535-7163.MCT-08-0716

[15] Wang, Y., Klijn, J.G., Zhang, Y., Sieuwerts, A.M, Look, M.P., Yang, F., Talantov, D., Timmermans, M., Meijer-van Gelder, M.E., Yu, J., Jatkoe, T., Berns, E.M., Atkins, D. and Foekens, J.A. (2005) Gene-Expression Profiles to Predict Distant Metastasis of Lymph-Node-Negative Primary Breast Cancer. The Lancet, 365, 671-679.

[16] Liu, N.Q., De Marchi, T., Timmermans, A., Trapman-Jansen, A.M., Foekens, R., Look, M.P., Smid, M., van Deurzen, C.H., Span, P.N., Sweep, F.C., Brask, J.B., Timmermans-Wielenga, V., Foekens, J.A., Martens, J.W. and Umar, A. (2016) Prognostic Significance of Nuclear Expression of UMP-CMP Kinase in Triple Negative Breast Cancer Patients. Scientific Reports, 6, Article No. 32027. https://doi.org/10.1038/srep32027

[17] Carvalho, C., Santos, R.X., Cardoso, S., Correia, S., Oliveira, P.J, Santos, M.S. and Moreira, P.I. (2009) Doxorubicin: The Good, the Bad and the Ugly Effect. Current Medicinal Chemistry, 16, 3267-3285. https://doi.org/10.2174/092986709788803312

[18] Coldwell, K.E., Cutts, S.M., Ognibene, T.J., Henderson, P.T. and Phillips, D.R. (2008) Detection of Adriamycin-DNA Adducts by Accelerator Mass Spectrometry at Clinically Relevant Adriamycin Concentrations. Nucleic Acids Research, 36, e100. https://doi.org/10.1093/nar/gkn439

[19] Swift, L.P., Rephaeli, A., Nudelman, A., Phillips, D.R. and Cutts, S.M. (2006) Doxorubicin-DNA Adducts Induce a Non-Topoisomerase II-Mediated Form of Cell Death. Cancer Research, 66, 4863-4871. https://doi.org/10.1158/0008-5472.CAN-05-3410

[20] Chen, S., Wang, X., Ye, X., Ma, D., Chen, C., Cai, J., Fu, Y., Cheng, X., Chen, Y., Gong, X. and Jin, J. (2017) Identification of Human UMP/CMP Kinase 1 as Doxorubicin Binding Target using Protein Microarray. SLAS Discovery, 22, 1007-1015. https://doi.org/10.1177/2472555217707704

[21] Zheng, R.R., Hu, W., Sui, C.G., Ma, N. and Jiang, Y.H. (2014) Effects of Doxorubicin and Gemcitabine on the Induction of Apoptosis in Breast Cancer Cells. Oncology Reports, 32, 2719-2725. https://doi.org/10.3892/or.2014.3513 
[22] Numakura, K., Tsuchiya, N., Akihama, S., Inoue, T., Narita, S., Huang, M., Satoh, S. and Habuchi, T. (2014) Successful Mammalian Target of Rapamycin Inhibitor Maintenance Therapy Following Induction Chemotherapy with Gemcitabine and Doxorubicin for Metastatic Sarcomatoid Renal Cell Carcinoma. Oncology Letters, 8, 464-466.

\section{Abbreviations}

UMP/CMP kinase 1, CMPK1; deoxycytidine kinase, DCK; gemcitabine monophosphate, dFdCMP; gemcitabine diphosphate, dFdCDP; gemcitabine triphosphate, dFdCTP; adenosine-5'-triphosphate, ATP; doxorubicin, DOX; cytidine 5'-monophoaphate, CMP; 2'-deoxy-CMP, dCMP; uridine 5'-monophosphate, UMP; $\beta$-L-dioxaolanetibine, L-OddC; 3'-dideoxy-3'-thiacytidine, 3-TC; anti-human immunodeficiency virus, HIV; $1-\beta$-D-arabinofuranosylcytosine, AraC; lymph-node negative, LNN; adjuvant systemic chemotherapy naive, ASCN; triple negative breast cancer, TNBC. 